\title{
Differential impacts of climate change on communities in the middle hills region of Nepal
}

\author{
Popular Gentle $\cdot$ Rik Thwaites $\cdot$ Digby Race $\cdot$ Kim Alexander
}

Received: 22 January 2014/ Accepted: 29 April 2014

(C) Springer Science+Business Media Dordrecht 2014

\begin{abstract}
There is a growing understanding that the impacts of climate change affect different communities within a country, in a variety of ways - not always uniformly. This article reports on research conducted in the middle hills region of Nepal that explored climate change vulnerability in terms of exposure, sensitivity and adaptive capacity across different well-being groups, genders of the head of household and household location. In the study region, dry land farming has increasingly experienced climate-induced changes to farm productivity and natural resources. The experience of vulnerability to decreased livelihood options and natural resource hazards due to a changing climate varied according to household wealth and well-being status, with very poor and poor households more vulnerable than medium and well-off households. The research indicates that the climate change adaptation would benefit by considering: (i) differential impacts of vulnerability mainly based on well-being status of households; (ii) understanding of the local sociopolitical context and underlying causes of vulnerability and its application; and (iii) identifying vulnerable populations for the units of vulnerability analysis and adaptation planning.
\end{abstract}

Keywords Climate change $\cdot$ Rural livelihoods $\cdot$ Vulnerability $\cdot$ Adaptive capacity · Nepal

Electronic supplementary material The online version of this article (doi:10.1007/s11069-014-1218-0) contains supplementary material, which is available to authorized users.

P. Gentle $(\square) \cdot$ R. Thwaites $\cdot$ D. Race $\cdot$ K. Alexander

School of Environmental Sciences, Charles Sturt University, PO Box 789,

Albury, NSW 2640, Australia

e-mail: pgentle@csu.edu.au

D. Race

The Fenner School of Environment and Society, The Australian National University,

Canberra, ACT 0200, Australia

K. Alexander

Wollongong University, Wollongong, NSW, Australia 


\section{Introduction}

Although climate change is a global phenomenon, the impacts are mostly local (Adger et al. 2004; IPCC 2007). The design and implementation of effective adaptation strategies requires local knowledge to cope with climate vulnerabilities (Gippner et al. 2012; Picketts et al. 2013). Many studies have confirmed differential impacts of climate change with higher vulnerabilities in: (i) developing countries (Ayers and Huq 2009; World Bank 2009); (ii) communities dependant on natural resource-based livelihoods (Agrawal and Perrin 2008; Paavola and Adger 2002); (iii) geographically remote areas (Kohler et al. 2010); (iv) poor within a society of class differences (Adger et al. 2003; Mirza 2010); and (v) women within the society and households based on gender differences (Terry 2009). Households dependent on the natural resource base for their livelihoods have been recognized as the most vulnerable communities in Nepal (Gentle and Maraseni 2012; GoN 2010).

Nepal has experienced increasing temperatures, erratic rainfall and the unpredictable onset of monsoon seasons, which has led to an increasing vulnerability to glacial lakes outburst floods (GLOF), and experiences of droughts, floods and landslides (MoE 2010). Warming in Nepal has been steadily increasing at an average annual rate of $0.06{ }^{\circ} \mathrm{C}$ with a higher rate of warming in the high-altitude mountains than in the lowland plains (Ebi et al. 2007; Shrestha et al. 1999). While monsoon and pre-monsoon precipitation have been heavier than previous records indicate, precipitation has become more unpredictable and more erratic with more droughts and shorter periods of winter rainfall (Duncan et al. 2013; Shrestha et al. 2000).

A projection of changes in temperature and precipitation is of great concern. The general circulation models (GCM) run underpin the Special Report on Emission Scenarios (SRES) B2 scenario, based on pre-2000 baseline data, predict an increase in mean annual temperature of $1.2{ }^{\circ} \mathrm{C}, 1.7{ }^{\circ} \mathrm{C}$ and $3{ }^{\circ} \mathrm{C}$ by $2,030,2,050$ and 2,100, respectively (Agrawala et al. 2003). Other predictions indicate that mean annual temperatures across Nepal may increase by: (i) $0.5-2.0{ }^{\circ} \mathrm{C}$, with a multi-model mean of $1.4{ }^{\circ} \mathrm{C}$, by the $2,030 \mathrm{~s}$; (ii) $1.7-4.1^{\circ} \mathrm{C}$, with a multi-model mean of $2.8^{\circ} \mathrm{C}$, by the $2,060 \mathrm{~s}$; and (iii) $3.0-6.3{ }^{\circ} \mathrm{C}$, with a multi-model mean of $4.7^{\circ} \mathrm{C}$, by the $2,090 \mathrm{~s}$ (NCVST 2009). Both studies predict higher temperature increases during winter than summer and higher temperature increments in western and central regions than in eastern regions of the country (GoN 2010). Precipitation projections indicate an increase in amount and intensity of monsoon and postmonsoon rainfall and a decrease in winter rainfall (GoN 2010). Spatial variation in both monsoon and winter precipitation is expected to continue with less rainfall in the western in comparison with eastern region (Agrawala et al. 2003; NCVST 2009). Run-off is expected to decrease in the long term with retreating glaciers and snow melt (Bates et al. 2008). High rates of glacial melt due to increased temperatures, and resultant glacial lake outburst floods (GLOF) are expected (Bates et al. 2008; Eriksson et al. 2009; Xu et al. 2007).

More than 1.9 million people are estimated to be highly vulnerable to climate changes and another 10 million are increasingly at risk in Nepal (GoN 2010, p. 11). The country is identified as one of the ten most climate vulnerable of the developing countries due to geography, poor physical infrastructure and low levels of social sector development (Agrawala et al. 2003; Saito 2012). The climate change risk atlas 2010 ranks Nepal as the fourth most vulnerable country based on its extreme vulnerable situation (Maple Croft 2010). The National Adaptation Program of Action (NAPA) of Nepal identifies glacial lake outburst flood (GLOF) drought, flood and landslide as major climatic hazards causing 
vulnerability (GoN 2010). Considering the urgency, climate change policy and a framework for local adaptation plans of action (LAPA) have been prepared in 2011 with a primary focus on addressing climatic hazards (GoN 2011a, b).

Although vulnerability is experienced locally, the causes of vulnerability lie at different social, geographical and temporal scales (Ribot 2010). However, limited studies have been conducted in developing countries that analyse and project vulnerabilities, and formulate effective adaptation policies and programs (Mertz et al. 2009). A micro-level climate change vulnerability has been analysed at household and community levels to identify: (i) major hazards increasing risks and vulnerability; (ii) most impacted livelihood resources; and (iii) the most vulnerable population (daze 2009). The micro-level vulnerability is important in Nepal in a context where social exclusion and marginalization remain a major obstacle for the empowerment and overall development of poor and marginalized people (Bennett et al. 2006; Murshed and Gates 2005). Due to lack of clear understanding of micro-level impacts and their relation with socio-political and cultural issues, the policy documents lack the notion of differential vulnerability, and the adaptation responses are planned mainly according to the nature and intensity of hazards and their impacts in different geographical locations. There is a strong need to review whether climate change is impacting different people in the community differentially.

This paper examines differential impacts of climate change vulnerability in the rural hills of Nepal to understand more about:

(i) What are the major climate-related hazards impacting livelihoods of local communities;

(ii) Which livelihood options are considered as most vulnerable by local communities; and

(iii) Who are most vulnerable to the impacts of climate change?

The following sections of the paper present the theoretical background of climate change vulnerability, a description of a case study in Nepal where a vulnerability assessment was undertaken, and the methods used to determine the theoretical and policy implications.

\section{Climate change vulnerability}

The term vulnerability has been originally derived and rooted in geography and natural hazards disciplines (Fussel 2007). However, it has gradually grown as a key element of research in various disciplines such as ecology, economics, anthropology, livelihoods and development and poverty (Adger 2006; Fussel 2007). Vulnerability approaches developed within different disciplines have been applied in understanding and analysing climate change vulnerability as climate change presents multi-scale problems including diverse actors, multiple stressors and multiple time scales (Adger 2006; Oreskes 2004). Vulnerability assessment has been approached in several ways such as the risk-hazard approach, pressure and release approach, resilience approach and integrated approaches (Adger 2006; Fussel 2007; O'Brien et al. 2007). The risk-hazard framework is based on technical literature related to risk and disaster management and it conceptualizes vulnerability as a relationship between an exogenous hazard to a system and its adverse effects (Burton 1997; Burton et al. 1993; Dilley and Boudreau 2001). The pressure and release model defines vulnerability linking types of physical hazards with underlying causes of vulnerability from the political economy approach (Blaikie et al. 1994; Pelling 2003). The political economy approach is based on poverty and development literature. 
The approach equates vulnerability with socio-economic vulnerability to multiple stresses (Fussel 2007).

A holistic approach to climate change vulnerability has been developed by the Intergovernmental Panel on Climate Change (IPCC) combining various methods on ecological, bio-physical and social vulnerability. The IPCC defines vulnerability as: "the degree to which a system is susceptible to, or unable to cope with the adverse effects of climate change, including climate variability and extremes. Vulnerability is a function of the character, magnitude, and rate of climate variation to which a system is exposed, its sensitivity, and its adaptive capacity" (IPCC 2001, p. 995). Based on this definition, exposure is considered as the magnitude and duration of the climate-related exposure due to climate-induced disasters and variability such as drought, flood, landslides and variability in average annual temperature and precipitation. Sensitivity is considered as the degree to which the system/major components are affected by the exposure such as sensitivity to health, food and water. Adaptive capacity is considered as the system's ability to withstand or recover from the exposure mainly based on socio-demographical profile and livelihood strategies. The state of exposure is usually based on geographical locations rather than individual and social characteristics (Adger 1999), while adaptive capacity of individuals and society varies according to inequality and social exclusion such as gender, ethnicity and socio-economic status (Ribot 2010).

Adger (1999) disaggregated vulnerability into individual and collective vulnerability to clarify the issues of scale and unit of analysis. As defined, individual vulnerability is caused by access to resources, income and social status of individual and households, whereas collective vulnerability is caused by institutional and market structures such as social security, insurance, infrastructure and income (Adger 1999, p. 252). Vulnerability of individuals and society is also linked to poverty as poverty is both a condition and determinant of vulnerability (Brown 2011; Tanner and Mitchell 2008). Sen (1999) describes the multidimensionality of poverty as insufficient outcomes related to health, nutrition and literacy, as well as with weak social relations, insecurity, low self-esteem and powerlessness. The poverty and climate change nexus describe that the poor in the developing world are already facing and are more likely to suffer from, the impacts of climate change-induced extreme events (Adger et al. 2003; Hedger et al. 2008; Tubiello and Fischer 2007). This is due to several factors inherent in developing countries: (i) current and projected physical impacts are relatively higher in developing countries (high temperatures and low precipitations); (ii) economic structures and livelihoods of a large population dependant on agriculture are very sensitive to climate change; (iii) relative proportions of the populations are poor with lower adaptive capacity; and (iv) economic and technical capacity of developing countries make it difficult to adapt to climate change (Mertz et al. 2009).

Climate change-related hazards such as droughts and flood create stress on rural livelihoods by reducing existing livelihood options and by creating volatility and unpredictability in streams of livelihoods benefits (Agrawal and Perrin 2008; Conway and Schipper 2011). The poor and marginalized are severely affected by the impacts of climate change due to settlement on marginal lands, high dependence on climate-sensitive livelihoods, limited livelihood options, inequitable access to productive assets, limited information, poor education, limited skills and inadequate access to services (Adger et al. 2003; Gentle and Maraseni 2012; IISD 2003; Paavola and Adger 2005). Institutional constraints such as lack of property rights and social protection further prevent poor people from investing their scarce resources in managing climate risks (IFRC 2004; Ribot 2010).

Methods and tools to analyse and assess climate vulnerability quantify both vulnerable livelihood options and adaptation strategies. Most of the analyses are based on IPCC's 
definition of vulnerability as a function of exposure, sensitivity and adaptive capacity (Ebi et al. 2006; Hahn et al. 2009; O'Brien et al. 2004; Polsky et al. 2007; Urothody and Larsen 2010; Vincent and Cull 2010). The Livelihood Vulnerability Index (LVI) was developed (Hahn et al. 2009) to quantify the vulnerability of different livelihood assets. The LVI is based on IPCC's framework (IPCC 2001) that defines vulnerability as a function of exposure, sensitivity and adaptive capacity. The LVI has been applied in micro-level vulnerability analyses (Hahn et al. 2009; Urothody and Larsen 2010), supported by participatory rural appraisal (PRA) (Chambers 1983, 1994; Chambers and Conway 1992) and other participatory tools in assessing livelihoods, vulnerabilities and risks related to disaster and climate change (Daze et al. 2009; de Dios 2002; Gaillard et al. 2013; Macchi 2011; Pasteur 2010). The use of these methods in this research is outlined in the following section.

\section{Case study location and research methods}

\subsection{Case study location}

The research was conducted in the Lamjung district of Nepal (Fig. 1). The district is located in the middle hills region of western Nepal where over two-thirds of the population of the district depends on subsistence agriculture with a strong linkage between farming, pasture lands and forestry. The population of the district in 2011 was 169,104 in 44,068 households (GoN 2012b). The district is ranked as one of the very high climate change vulnerable districts in Nepal based on high vulnerabilities due to landslides and GLOF (GoN 2010). The district has a diverse mixture of people in terms of caste, culture and ethnic identity with a mixed population of indigenous castes (Gurung, Magar, Tamang, Dalits). The research was conducted in four Village Development Committees (VDCs) of the district, two from the downstream (altitude about $500 \mathrm{~m}$ ) and two from upstream region with altitude above $1000 \mathrm{~m}$ along the Marsyangdi River. One community forest user groups (CFUG) each from the selected VDCs were selected as research units (Fig. 1). The CFUG is one of the largest community-based organizations in Nepal that includes over $40 \%$ of total population in Nepal comprised of more than 17,500 groups and responsible to manage 1.2 million ha (36\% of total) forest resources in Nepal (DoF 2011).

\subsection{Research methods}

A mixed method approach was used based on pragmatism using an interpretivist perspective (Johnson et al. 2007; Tashakkori and Teddlie 2003). The perspective links quantitative data collection methods with social science-based qualitative methods those often deal with individual actions and their relationship with society. The political ecological approach had a complementary role in linking ecological, social and political dimensions from critical paradigms in this research (Springate-Baginski and Blaikie 2007). Qualitative methods as a primary technique of data collection included: in-depth interviews ( $n=62$ interviewees), focus group discussions (FGDs) $(n=11$ events with 117 participants) and participant observations. A household level survey $(n=133$ respondents) provided quantitative data. The research adopted a multi-scaled and multiphased data collection process. Data collection was carried out at community, district and national level in three phases focusing on various actors related to the research. 


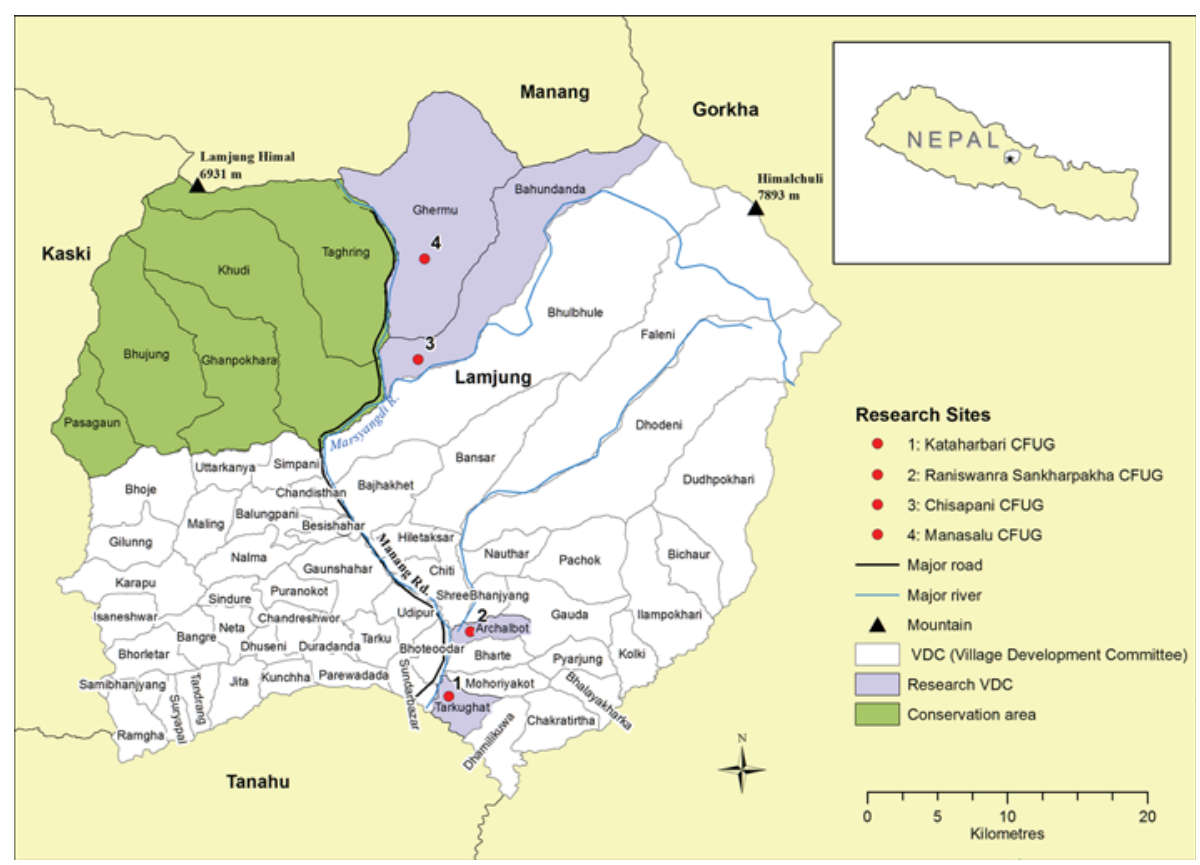

Fig. 1 Location of the research areas

The primary data were collected through two field trips in Nepal, the first field work from December 2011 to April 2012 and the second in May 2013. The first fieldwork focused on collecting data at community and district levels. Following the analysis of community and district level data, the second field programme focused on national level data. In addition to the primary data, secondary data were collected from different organizations and institutions related to the research. The meteorological data on temperature and precipitation records (1971-2010) from nearby Khudi weather station were obtained from Department of Hydrology and Meteorology (DHM), Nepal.

Participatory well-being ranking was conducted in the research sites to categorize the research households into four well-being strata (well-off, medium, poor and very poor) based on the relative well-being position of households in the community using local criteria of well-being (Mosse 1994). The empirical validity of this method as a means of socio-economic stratification of households has been tested by different researchers in Nepal and abroad (Adams et al. 1997; Gentle and Maraseni 2012; Richards et al. 2003; Scoones 1995; Sharma 2010; Sharma and Filius 1999). Most common criteria used were: assets such as landholding size, quality of land, quality of house, food sufficiency, income sources, status of money lending and borrowing, number and quality of livestock, as well as educational and social status of the family (Table 1).

Survey respondents and interviewees for in-depth interview were selected using a stratified random sampling process and represented all well-being groups. Vulnerability indicators developed and applied by Hahn et al. (2009) to estimate livelihood vulnerability of two districts in Mozambique were updated in the Nepalese context and applied to 
Table 1 Local criteria of well-being developed and applied by research participants

\begin{tabular}{|c|c|c|c|c|}
\hline \multirow{2}{*}{$\begin{array}{l}\text { Local criteria } \\
\text { of wellbeing }\end{array}$} & \multicolumn{4}{|c|}{ Characters of different well-being groups } \\
\hline & Well-off & Medium & Poor & Very Poor \\
\hline $\begin{array}{l}\text { Food } \\
\text { production } \\
\text { and } \\
\text { sufficiency }\end{array}$ & $\begin{array}{l}\text { Food production } \\
\text { enough for the year, } \\
\text { sale of surplus } \\
\text { products }\end{array}$ & $\begin{array}{l}\text { Food production } \\
\text { enough for around } \\
\text { nine-month } \\
\text { period }\end{array}$ & $\begin{array}{l}\text { Food production } \\
\text { enough for } \\
\text { around six- } \\
\text { month period }\end{array}$ & $\begin{array}{l}\text { Food production } \\
\text { enough for three } \\
\text { months or less }\end{array}$ \\
\hline $\begin{array}{l}\text { Size and } \\
\text { quality of } \\
\text { agriculture } \\
\text { land }\end{array}$ & $\begin{array}{l}\text { Large size of } \\
\text { irrigated and non- } \\
\text { irrigated land }\end{array}$ & $\begin{array}{l}\text { Limited irrigated } \\
\text { and some non- } \\
\text { irrigated land }\end{array}$ & $\begin{array}{l}\text { Limited irrigated } \\
\text { and non- } \\
\text { irrigated land }\end{array}$ & $\begin{array}{l}\text { Mostly landless or } \\
\text { small parcel of non- } \\
\text { irrigated land }\end{array}$ \\
\hline $\begin{array}{l}\text { Sources of } \\
\text { employment }\end{array}$ & $\begin{array}{l}\text { Additional source of } \\
\text { income (job, } \\
\text { pension, remittance } \\
\text { or business) in } \\
\text { addition to } \\
\text { agriculture }\end{array}$ & $\begin{array}{l}\text { Additional source } \\
\text { of income (job, } \\
\text { pension, } \\
\text { remittance or } \\
\text { business) in } \\
\text { addition to } \\
\text { agriculture }\end{array}$ & $\begin{array}{l}\text { Mostly depend on } \\
\text { agriculture and } \\
\text { some } \\
\text { remittances, also } \\
\text { sell labour to the } \\
\text { local market }\end{array}$ & $\begin{array}{l}\text { Sell labour to the } \\
\text { local market }\end{array}$ \\
\hline $\begin{array}{l}\text { Social status } \\
\text { in the } \\
\text { community }\end{array}$ & $\begin{array}{l}\text { Mostly higher caste, } \\
\text { occupy major } \\
\text { positions in the } \\
\text { local institutions }\end{array}$ & $\begin{array}{l}\text { Mostly higher and } \\
\text { medium caste, } \\
\text { occupy some } \\
\text { positions in the } \\
\text { local institutions }\end{array}$ & $\begin{array}{l}\text { Mostly from } \\
\text { medium or } \\
\text { lower caste, } \\
\text { rarely hold } \\
\text { positions in } \\
\text { local institutions }\end{array}$ & $\begin{array}{l}\text { Mostly from lower } \\
\text { caste, generally not } \\
\text { in any positions of } \\
\text { local institutions }\end{array}$ \\
\hline Education & $\begin{array}{l}\text { Most of the family } \\
\text { members educated, } \\
\text { children admitted } \\
\text { to private schools } \\
\text { and sent to urban } \\
\text { cities for education }\end{array}$ & $\begin{array}{l}\text { Family members } \\
\text { partially } \\
\text { educated, children } \\
\text { admitted to local } \\
\text { private schools or } \\
\text { public schools }\end{array}$ & $\begin{array}{l}\text { Few members in } \\
\text { the family are } \\
\text { educated, } \\
\text { children } \\
\text { admitted to } \\
\text { public schools }\end{array}$ & $\begin{array}{l}\text { Family members are } \\
\text { rarely educated, } \\
\text { children either } \\
\text { admitted to public } \\
\text { schools or dropped } \\
\text { from the schools }\end{array}$ \\
\hline $\begin{array}{l}\text { Money } \\
\text { lending and } \\
\text { borrowing }\end{array}$ & $\begin{array}{l}\text { Lend money in the } \\
\text { local community }\end{array}$ & $\begin{array}{l}\text { Occasionally lend } \\
\text { money in the } \\
\text { community }\end{array}$ & $\begin{array}{l}\text { Loan borrowed } \\
\text { for household } \\
\text { needs }\end{array}$ & $\begin{array}{l}\text { Consumption loan } \\
\text { borrowed from local } \\
\text { lenders and } \\
\text { indebted }\end{array}$ \\
\hline
\end{tabular}

estimate livelihood vulnerability according to well-being status, location of villages and gender of household head of the respondents. Descriptive information generated from the survey based on 34 sub-components has been grouped into eight major components and three vulnerability factors to form the LVI (Table 2 and Appendix 1 in supplementary material).

Descriptive and quantitative data collected from the randomized household survey were framed by the data needs of the LVI, with this data analysed using the Statistical Package for the Social Sciences (SPSS) and significance of mean values were confirmed by using Pearson's chi-square test. Qualitative data arising from interviews, FGDs and observations on individual hazards and vulnerability were analysed based on a thematic hierarchy approach (King and Horrocks 2010) using NViVO 10 and presented in the forms of frequency, charts, quotes and comparisons. 
Table 2 Vulnerability factors, components and sub-components applied to develop LVI

\begin{tabular}{|c|c|c|}
\hline $\begin{array}{l}\text { Vulnerability } \\
\text { factors }\end{array}$ & Major components & Sub-components \\
\hline \multirow[t]{2}{*}{ Exposure } & Natural disasters & $\begin{array}{l}\text { Average number of hazards in the past } 6 \text { years } \\
\text { Receiving warning about natural disasters } \\
\text { Injury or death as a result of natural disaster } \\
\text { Loss/damage of physical properties as a result of natural disaster }\end{array}$ \\
\hline & Climate variability & $\begin{array}{l}\text { Mean standard deviation of monthly average of average } \\
\text { maximum daily temperature } \\
\text { Mean standard deviation of monthly average of average } \\
\text { minimum daily temperature } \\
\text { Mean standard deviation of monthly average precipitation }\end{array}$ \\
\hline \multirow[t]{3}{*}{ Sensitivity } & Health & $\begin{array}{l}\text { Average time to reach basic health facility } \\
\text { Affordability of basic health services } \\
\text { Household with chronic ill members } \\
\text { Household members missing school or work due to illness } \\
\text { Average mosquito exposure prevention } \\
\text { Household having toilet in use } \\
\text { Household using LPG or other smokeless stoves }\end{array}$ \\
\hline & Food & $\begin{array}{l}\text { Food sufficiency } \\
\text { Average crop diversity } \\
\text { Saving seeds }\end{array}$ \\
\hline & Water & $\begin{array}{l}\text { Dependency on natural water sources } \\
\text { Reported water conflict issues } \\
\text { Average time to get water source } \\
\text { Consistency of drinking water supply }\end{array}$ \\
\hline \multirow[t]{3}{*}{$\begin{array}{l}\text { Adaptive } \\
\text { capacity }\end{array}$} & $\begin{array}{l}\text { Socio-demographical } \\
\text { profile }\end{array}$ & $\begin{array}{l}\text { Dependency ratio of family members } \\
\text { Female-headed households } \\
\text { Households with/without television, radio or telephone }\end{array}$ \\
\hline & Livelihood strategies & $\begin{array}{l}\text { Family members working in different community for casual work } \\
\text { Landless or land poor households } \\
\text { Dependency on agriculture as a main source of income } \\
\text { Average agricultural livelihood diversification } \\
\text { Household with/without irrigation facility to grow primary crops }\end{array}$ \\
\hline & Social networks & $\begin{array}{l}\text { Ratio of getting and providing support in a social network } \\
\text { Borrowing money from social networks } \\
\text { Borrowing money from private money lenders for consumption } \\
\text { Visiting local government office to seek services }\end{array}$ \\
\hline
\end{tabular}

\section{Results and discussion}

4.1 Major hazards and most impacted livelihoods resources

Interviewees $(n=62)$ were asked to describe the major climate-related hazards (maximum three per interviewee) and to relate these to the most impacted livelihood resources (maximum three per interviewee). Interviewees identified all together nine hazards they considered to be directly impacting their livelihoods. These hazards included features of changing weather patterns and impacts on natural resources including: erratic rain and snowfall, unusual or unseasonal frost, increasing incidence of landslides, gully formation from increased precipitation and erratic hailstorm and winds. Hazards related to farm productivity included increasing coverage of invasive weeds, increasing incidence of crop damage from insects and crop diseases and increasing incidence of livestock diseases. In 
addition, there were more extremely hot and cold days, which threaten agricultural production, livestock and communities. The perception of communities with respect to changing temperature has been compared with meteorological data (1971-2010) available from the nearby Khudi reading station. The analysis shows that both mean annual maximum and minimum temperature were constantly increasing with high variations.

The most vulnerable livelihood resources mentioned by the interviewees were paddy cultivation, cultivation of other crops and vegetables, drying water sources, livestock, forages and condition of grazing land, farmlands, forests, orange farming and the transhumance pastoral system. The responses of interviewees are presented in Fig. 2 to show direct linkages (impacts) between each hazard and livelihood resources.

\subsubsection{Major hazards and their impacts}

Fifty-six $(90 \%)$ interviewees reported erratic rain and snowfall as a most common hazard, described as erratic snowfall by interviewees from high-altitude villages. Erratic rain and snow were mentioned as a hazard as it was: (i) causing delayed planting of crops; (ii) decreasing water availability with unseasonal water recharge in the local water sources; (iii) affecting growth and production of crops; (iv) damaging crops during the harvesting season; and (v) increasing uncertainty in farming productivity. Erratic rain and snowfall were major causes of crop failure and decreased production of primary crops, lowering productivity of pastures. The hazard had a direct impact on livelihoods as most of the primary crop production was based on rain-fed cultivation. The meteorological data (1971-2010) obtained from the nearby Khudi reading station show that the pattern of average annual, monsoonal and winter precipitation was erratic. The historical timeline prepared by research participants indicates that the rainfall pattern has been more erratic in the last 20 years in comparison with the past.

Twenty-five $(40 \%)$ interviewees mentioned frost as an emerging hazard for winter crops. Interviewees who reported frost as a hazard planted winter crops, mainly potato, in the lowlands along the river basins. Most of the interviewees claimed that frost had appeared in their village in recent years. One of the interviewees reported "we never had frost in this area in the past but it is now common in every winter for the last 10 years and it is damaging our winter crops every year". Historical timelines prepared by the research participants revealed that damage of winter crops by frost had been observed from 1999 onwards. Twenty-five (40\%) interviewees mentioned landslide and gully development as devastating hazards. Landslides were differentially experienced by interviewees from different well-being groups and in different areas, in rural, residential and communal lands (Fig. 3).

In Fig. 3, the well-off and medium respondents reported landslide- and flood-affected farmlands and communal lands such as forests, roads and pastures. Landslides and floods were reportedly more hazardous to very poor and poor households by impacting their residential areas and farmlands as most of them were living close to landslide and flood prone areas. One of the very poor interviewees from Raniswanra CFUG explained "we had a landslide close to our house so we feel stress in the rainy season because of landslide. Sometime we can't sleep the whole night because of our fear of the threat". Hazard and livelihood maps indicated that most of the very poor households were living in marginal (unproductive and sloppy) lands close to landslide prone areas.

Emergence and expansion of unwanted weeds such as Nilo Gandhe (Ageratum houstonianum) and Banmara (Eupatorium odoratum) were reported as hazards by 20 (32\%) interviewees mainly from downstream villages. The Nilo Gandhe was reported 


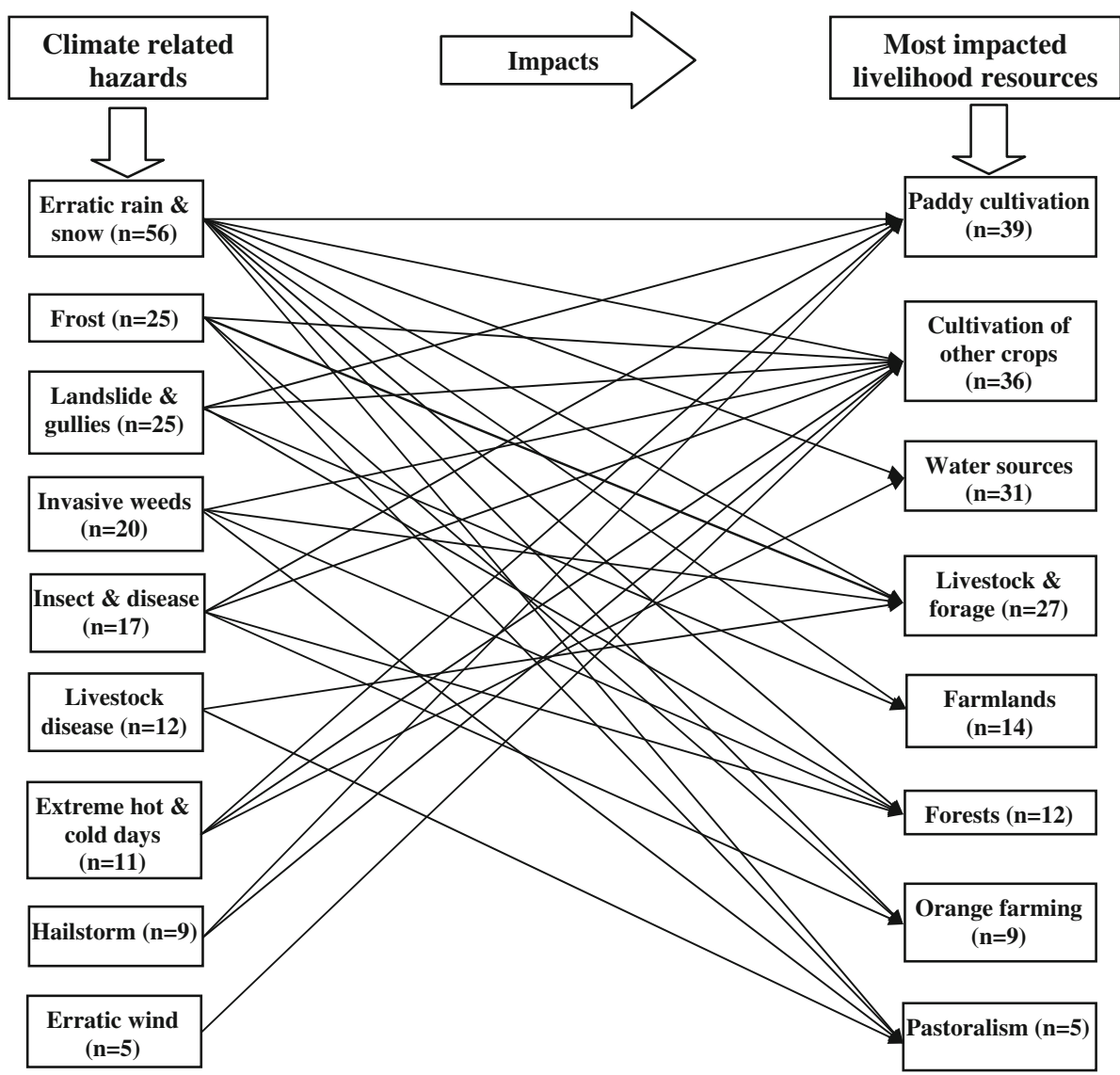

Fig. 2 Major hazards and most impacted livelihood resources. Source: Analysis of interview transcriptions

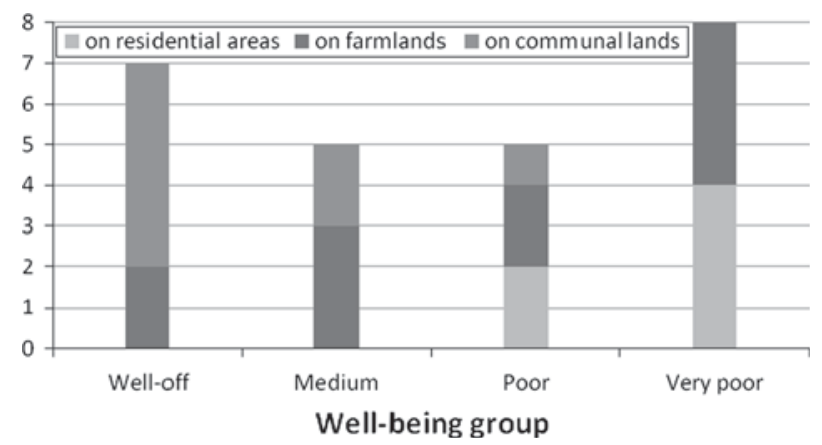

Fig. 3 Number of people experienced landslide, flood and gullies in different land use practices. Source Analysis of interview transcription

as a common weed in the farmlands which was replacing many nutritious grasses and limiting agriculture production. The transhumance pastoralists from Manasalu CFUG in the upstream reported that when they bring their sheep and goats in the downstream 
villages in the winter, they face scarcity of grass in the grazing lands due to invasive weeds.

Increasing number of insects and crop diseases was reported as one of the hazards by 17 $(27.4 \%)$ interviewees. Common insects and diseases in the farmlands were reported as Lie (aphids) in the legumes, Gabaro (stem borer) in the maize, Patero (rice bug) and Kalo Poke (rust) in the paddy and Dadhuwa (blight) in potatoes and other winter crops. Increasing incidence of livestock diseases was reported as a major hazard by 12 (19\%) interviewees. Diseases were experienced by goat owners in the recent years. One of the agriculture service providers mentioned increasing trends of livestock diseases in the hills which were uncommon in the past. As he mentioned "in the past livestock diseases were common in Terai and there were not many livestock diseases in the hills. Now there are many livestock deaths in the hills due to diseases. It may be due to increasing warming days and extreme cold days in the winter".

Extreme hot and cold days were reported as a major hazard by $11(18 \%)$ interviewees. One of the interviewees (district level NGO leader) described a shorter winter period in recent years in comparisons with the past. As explained "in the past cold days remained up to Chaitra (spring) but now there is no cold after Magh (winter). We used to have cold days from Aashauj (autumn) but we feel cold only after Kartik (late autumn)". Nine interviewees reported that the erratic nature of hailstorm was a hazard to their crops. Maize farmers in the high-altitude villages claimed damages of maize crops due to unseasonal winds.

\subsubsection{Most vulnerable livelihood options}

Paddy cultivation was mentioned as most vulnerable by $63 \%$ of interviewees as there was uncertainty in planting time due to erratic rainfall, inadequate water following the planting of seedlings, damage of crops by erratic rainfall, damage of paddy fields by landslide and floods and damage by insects and diseases. As reported by a very poor interviewee, "We have to wait for rainfall. We used to grow paddy but we do plant millet where there is no irrigation facility". A well-off farmer from Manasalu CFUG explained "this year we had weeklong unusual rainfall in the Mangsir (during the paddy harvesting time in late autumn) which had damaged paddy and straw". The availability of irrigation facilities was found to be crucial in determining crop loss in the face of erratic rainfall. Survey data revealed that altogether $67 \%$ of respondents had irrigation facility to grow their primary crops including $95 \%$ of well-off, $76 \%$ medium, $48 \%$ poor and $6 \%$ very poor households. The irrigation facility to produce primary crops has a significant association with well-being status $(P<0.01)$ of the respondents.

Thirty-six $(58 \%)$ interviewees reported cultivation of crops such as potato, maize, mustard and green vegetables as most vulnerable. According to the interviewees, major causes of vulnerability of these crops were increasing frequency and duration of frost, erratic rainfall, increasing damage by insects and diseases, hailstorm, wind and invasive weeds. Survey data indicated that about $95 \%$ of respondents (total respondents $=133$ ) reported crop loses or reduction in crop production in recent years due to climate-related reasons.

Thirty-one $(50 \%)$ of interviewees reported drying water level in their traditional sources such as spring-fed ponds, rain-fed ponds and streams. As reported, drying water sources increased stress and caused livelihood vulnerability due to: (i) scarcity of drinking water; (ii) inadequate water in irrigation canals; (iii) decreasing production of agriculture crops; (iv) internal migration of people due to water scarcity; and (v) conflicts in water use. 
As one interviewee said, "Water sources are gradually drying everywhere. We were 30 families in this village in the past, now we are only 12 families as other families migrated to Besi area. The drinking water was enough for all families in the past but it is not enough even after migration of more than $60 \%$ households as the source has dried". A very poor interviewee from Raniswanra expressed a story of displacement of a community due to water scarcity. As described: "water in our wells, streams and river is decreasing. The wells where we used to fetch drinking water are now almost dried. There was a small village near ours but there is not a single house now. The village has been displaced due to scarcity of water".

Twenty-seven (44\%) interviewees reported climate change impacts on livestock, livestock forages and grazing lands. Livestock were dying due to extreme cold- and temperature-related diseases. Interviewees described that the livestock forages have decreased in the farm and grazing lands due to expansion of invasive weeds mainly the Nilo Gandhe and Banmara. Interviewees also reported that the damage to straw due to erratic rainfall during the paddy harvesting season caused shortage of forages and became a source of diseases for many livestock. According to survey data, about $60 \%$ of the respondents $(n=133)$ reported losing livestock production due to reduced numbers of livestock and thus less production of milk, meat and compost in recent years. The reported loss in livestock production significantly varied according to well-being status of the respondents $(P<0.01)$ with higher losses for the very poor followed by poor, medium and well-off households.

Fourteen $(23 \%)$ interviewees described that their farmlands were increasingly being damaged by landslides, floods and gully development. Twelve (19\%) interviewees reported various impacts on forests, reported as: (i) loss of forest regeneration and growth of native plants from invasive weeds; (ii) landslides in the forests; (iii) damage by insects and caterpillars; and (iv) forest fires. Nine (15\%) interviewees reported loss of orange trees. Five $(8 \%)$ interviewees claimed that the transhumant pastoral system has become more vulnerable due to scarcity of grasses in the pastures, shortage of water and increasing livestock diseases. Impacts on agriculture crops were mostly reported by those depending on agriculture as a primary occupation, as well as by very poor and poor interviewees share cropping on rented land.

The research revealed that almost all local communities have already experienced climate change and its impacts on their livelihoods. However, impacts of hazards reported by communities varied according to the well-being status, geographical location and occupation of the communities. For example, invasive weeds, mosquitoes, increasing pests and diseases in the farms were reported as major hazards by the research participants residing in downstream villages. The impacts of erratic snowfall and wind were common in the upstream villages above $1000 \mathrm{~m}$. Frost was reported as a new hazard by the farmers who were cultivating winter crops such as potatoes, mustard and other vegetables in the Besi area along the river corridor. Scarcity of drinking water was a result of gradually drying water sources, more commonly found in the uplands. The analysis above presents differential impacts of climate change according to different geographical locations and occupations. The analysis considers impacts of climate change as environmental issues caused by natural hazards. However, a deeper analysis of the hazards and their impacts showed many linkages between climate change impacts and socio-political structure of the society. For example, erratic rainfall was one of the major causes of declining agriculture productivity. However, the impacts were greater for poor families who were cultivating in rain-fed uplands. The significant association between well-being of the households with irrigation facilities to 
grow primary crops confirmed that the very poor and poor households lacking irrigation facilities suffered more from erratic rainfall.

Increasing occurrence of landslides was impacting farmland, residential areas, forests and other public and communal lands. However, the impacts were experienced differently by different households. More than two-thirds of very poor and almost all Dalit families were historically living in landslide prone areas in all research villages. The landslide and gullies had severe impacts on those living close to landslide prone areas, farming their crops in the marginal slopes. Households were mostly landless, indebted and had a poor social network. The hazards were not only impacting the physical resources, the households living close to these hazards were experiencing threats and psycho-social stress. The analysis confirmed that the impact of landslides on livelihoods was related to historical marginalization processes where powerless households and communities were compelled to live in the marginal lands.

A majority of the interviewees reported that water sources were gradually drying. The water sources were traditionally used for drinking water, sanitation, livestock feeding and small-scale irrigation. In recent years, drinking water systems had been installed in most of the villages with common taps in each cluster. However, nearly half of very poor households were still dependent on traditional drinking water sources such as wells and streams and over $87 \%$ of these households were facing water stress and water use conflicts. In many cases, the public taps were far from the settlement of very poor households as they were living in isolated marginal lands or were not able to afford maintenance fees and depended on the traditional and natural water sources. Likewise, the prevalence of mosquitoes was greater in the lower altitude villages. However, prevention of mosquitorelated impacts significantly $(P<0.01)$ varied according to the well-being status of the households as very poor and poor households could not afford to buy protective bed nets. The results confirms that the poor within the communities are differentially affected by the impacts of climate change due to settlement on marginal lands, high dependence on climate-sensitive livelihoods, limited livelihood options, inequitable access to productive assets, limited information, poor education, limited skills and inadequate access to services.

\subsection{Most vulnerable communities}

Climate change vulnerability was tested to examine the vulnerable communities according to their well-being status, gender of household head and location of the respondents (CFUG). The LVI was used to examine the vulnerability in terms of exposure, sensitivity and adaptive capacity. Exposure was measured in terms of natural disasters and climate variability; sensitivity was measured in terms of impacts on health, food and water; and the adaptive capacity was measured in terms of socio-demographical status, livelihood strategies and social network of the respondents (Survey results for indicators of each of these factors is given in Appendix 1 in supplementary material). The participatory hazard and resource maps prepared by research participants also confirmed who are most vulnerable in the community.

\subsubsection{Livelihood vulnerability according to well-being status of the respondents}

Results indicated that the vulnerability factors (exposure, sensitivity and adaptive capacity) varied according to well-being status of respondents (Fig. 4). Although exposure to climate change varied according to well-being status with very poor and poor more exposed to 
natural disasters than well-off and medium respondents, the difference was not significant. Sensitivity in terms of impacts on health, food and water, as components, was found significantly different according to well-being status of the respondents $(P<0.01)$.

Major differences in the health component according to well-being status were mainly due to: (i) lower affordability of health services and facilities by very poor and poor households; (ii) higher percentage of family members with chronic illness among very poor and poor households; (iii) higher mosquito exposure index among very poor and poor due to lack of bed net and other preventive measures; (iv) higher number of households among very poor and poor without a toilet in use; and (v) lower percentage of very poor and poor households with smokeless stoves in comparisons with well-off and medium respondents. The differences in food component were mainly due to: (i) higher average food deficit months among very poor and poor households; and ii) lower crop diversity among very poor and poor households in comparisons with the well-off and medium respondents. Likewise, the differences in water component were due to: (i) higher percentage of very poor households using natural sources for drinking water; (ii) higher percentage of very poor and poor households reporting problems related to water conflict and availability; and (iii) higher average time taken to fetch drinking water by very poor and poor households in comparisons with well-off and medium households.

The adaptive capacity of respondents was also significantly different according to wellbeing status of the households $(P<0.01)$. Differences were mainly due to: (i) higher dependency ratio of family members among poor and very poor households; (ii) high percentage of uneducated household head among very poor and poor households; (iii) high percentage of very poor and poor households without means of information and communication; (iv) high percentage of very poor and poor households working in a different community as a source of income; (v) low agriculture diversification among very poor and poor households; (vi) small landholding size or landlessness among very poor and poor households; and (vii) less irrigation facility to grow primary crops by very poor and poor households in comparisons with well-off and medium households. Differences in adaptive capacity were also due to poor social network of very poor and poor households in comparisons with well-off and medium households. The main differences were: (i) lower percentages of very poor and poor households borrowing money from their social network; (ii) higher percentage of very poor and poor households borrowing money from local landlords at high interest rate and indebtedness; and (iii) less service seeking practices from nearby VDCs by very poor and poor households in comparisons with well-off and medium households.

This analysis confirmed that climate change results in a differential vulnerability (in terms of sensitivity and adaptive capacity) with significant association between climate change vulnerability and well-being status of the communities.

\subsubsection{Livelihood vulnerability according to location of the respondents}

The livelihood vulnerability slightly varied according to location of households in different CFUGs (Fig. 5). The exposure was reported higher in Chisapani CFUG due to: (i) higher events of natural disasters such as floods and landslides; (ii) higher number of injuries as a result of natural disasters; and (iii) more damage of properties such as houses, land and livestock as a result of natural disasters in comparisons with other CFUGs. The overall sensitivity was higher in Kataharbari and Chisapani CFUGs in comparisons with Manasalu and Raniswanra CFUGs. The sensitivity of health component was higher in Manasalu CFUG, whereas the sensitivity on food and water components was higher in Kataharbari 


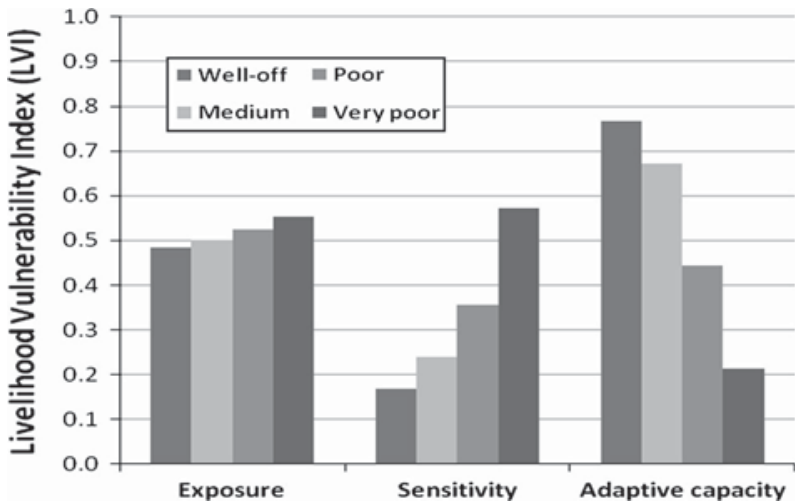

Fig. 4 Livelihood vulnerability according to well-being status of the respondents. LVI values $0=$ low to $1=$ high. Source Analysis of survey data

CFUG. The adaptive capacity in terms of dependency ratio was relatively lower in Chisapani CFUG, and the livelihood strategies and social network were relatively higher in Raniswanra and Chisapani CFUGs. The Chisapani CFUG has higher rate of exposure, sensitivity and adaptive capacity in comparison with other CFUGs. Despite these differences, no significant relationship was observed between the location of respondents with exposure $(P>0.05)$, sensitivity $(P>0.05)$ and adaptive capacity $(P>0.05)$ as major factors of vulnerability.

The analysis shows that there was not a uniform pattern or trend between vulnerability factors and components with location of households rather it was more random. Although the location of CFUGs varied according to altitude, livelihood opportunities, distance from service centres and ethnicity of the households, the differences were not significant and decisive factor in defining level of vulnerabilities.

\subsubsection{Livelihood vulnerability according to gender of household head}

Livelihood vulnerability was also analysed according to gender of the household head (Fig. 6). The survey data show that the proportion of male- and female-headed households was $71 \%(n=74)$ and $29 \%(n=39)$, respectively. The analysis of vulnerability according to household head was relevant in the rural context of Nepal as number of female-headed households was rapidly increasing mainly due to migration of male members to the Gulf and other countries as migrant labourers for remittance purpose. According to the population census carried out in Nepal in 2011, the female-headed households in the country have increased from $14.87 \%$ in 2001 to $25.73 \%$ in 2011 (GoN 2012a, p. 3). In the research area, the percentage of female-headed households was higher than the national average. Among the female-headed households, $54 \%$ had male members who had migrated overseas as labourers, $31 \%$ were headed by females as widow, and in $15 \%$ of households male members were living in other parts of the country. According to well-being status, very poor households had the highest percentage $(37 \%)$ of femaleheaded households followed by well-off (32\%), medium $(30 \%)$ and poor $(21 \%)$ households.

The analysis shows that female-headed households, in general, had slightly higher exposure and sensitivity and lower adaptive capacity in comparisons with male-headed 


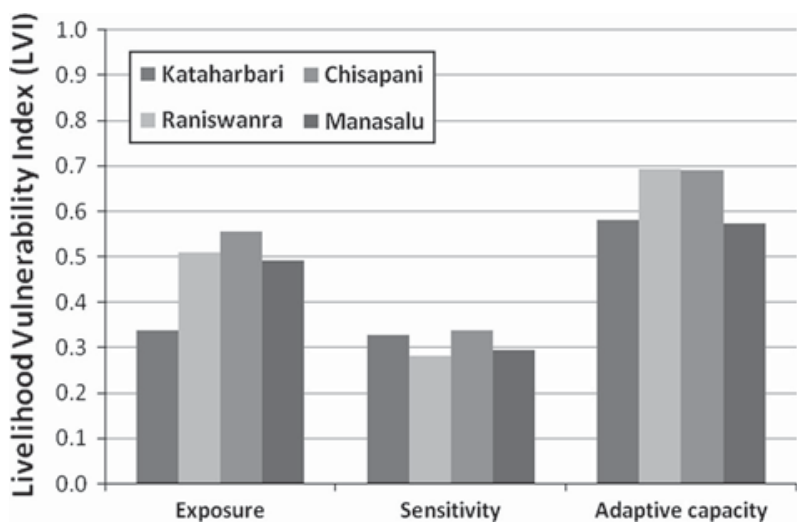

Fig. 5 Livelihood vulnerability according to location of respondents. LVI values $0=$ low to $1=$ high. Source Analysis of survey data

Fig. 6 Livelihood vulnerability according to gender of household head. LVI values $0=$ to low to $1=$ high. Source analysis of survey data

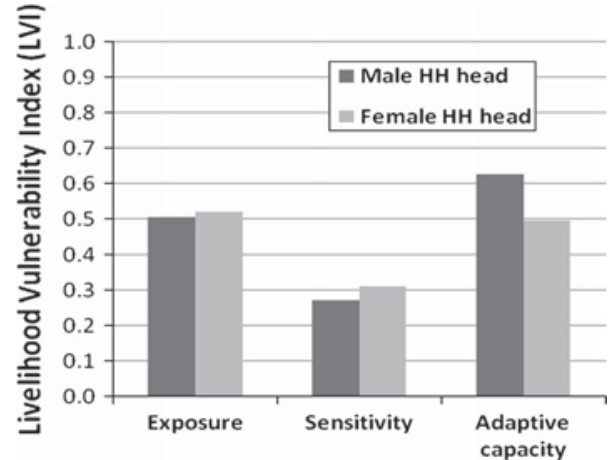

households (Fig. 6). The exposure was slightly higher among female-headed households as higher number of female-headed households reported more events of natural disasters such as floods and landslides; and more injuries due to natural disasters. The difference in sensitivity was due to: (i) higher impacts on health component encountered by femaleheaded households such as low affordability to health services; (ii) higher average mosquito prevention index due to lower number of bed nets; and (iii) less number of toilets in use by female-headed households. Likewise, average food deficit was higher and average crop diversity was low among female-headed households in comparisons with maleheaded households.

The female-headed households also reported higher dependency on natural sources of drinking water, spending higher time in fetching water and depending more on inconsistent supply of drinking water than male-headed households. Female-headed households had lower percentages of household heads who had attended school and higher percentage of households having communication means such as radio, television and mobile phone in comparisons with male-headed households. The female-headed households were receiving less support from their social networks and less frequently visiting their VDC office for basic services in comparisons with male-headed households. Despite these differences, no significant association was observed between gender of household head with exposure 


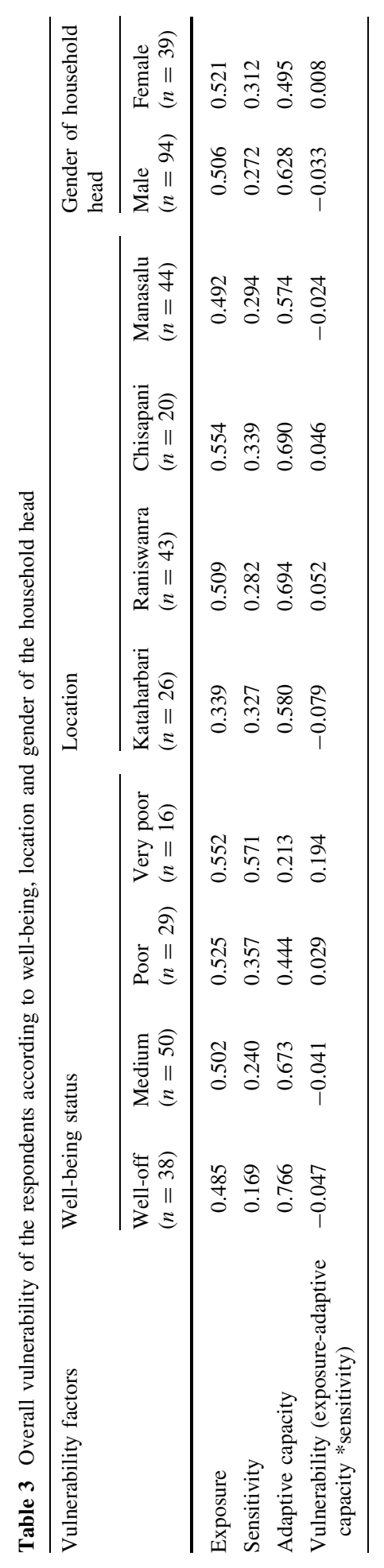


$(P>0.05)$, sensitivity $(P>0.05)$ and adaptive capacity $(P>0.05)$ as major factors of vulnerability.

\subsection{Overall vulnerability}

The overall climate change vulnerability according to IPCC's definition (Vulnerability $=$ exposure - adaptive capacity $\times$ sensitivity) showed differential vulnerability according to well-being status of the respondents. The very poor well-being groups were most vulnerable followed by poor, medium and well-off respondents. The overall vulnerability of Raniswanra was found higher followed by Chisapani, Manasalu and Kataharbari CFUG. Likewise, the overall vulnerability of female-headed households was found higher than male-headed households (Table 3), derived from household survey data.

This analysis of climate change vulnerability confirms that although livelihood vulnerability varies according to well-being status, location of households and gender of household head, the well-being status of households was the only tested characteristic that produced a significant difference in vulnerability factors and that only for sensitivity and adaptive capacity. Exposure was not found to vary significantly with well-being status of households. The other characteristics of location (CFUG) and gender of household head were not found to significantly influence exposure, sensitivity or adaptive capacity.

\section{Conclusions}

The research findings conclude that the local communities in the middle hills region of Nepal are already experiencing impacts of climate change in their livelihoods. The rain-fed and subsistence agriculture are mostly impacted by various climatic hazards together with other non-climatic factors. The erratic rainfall, increasing trend of drying water sources, prevalence of invasive weeds, increasing trend of pest, diseases and frost show a trend that subsistence farming in the rural hills of Nepal will become more challenging with the impacts of climate change. The findings presented in this article provide empirical evidence from a context where there is a very limited information and knowledge available on climate change impacts and vulnerability.

The research findings confirm that climate change has differential impacts. Although the climate change vulnerability varies according to location of communities, occupation, gender of household head, the overall vulnerability largely varies according to well-being status of the households within the communities. Major differences were due to higher sensitivity of very poor and poor households on food, water and health components and lower adaptive capacity in terms of poor socio-demographical status, limited livelihood diversification strategies and a weak social network. The findings show similarity with Ribot's (2010) research that describes that the socio-economic, institutional and policy dimensions of the households and communities govern sensitivity and adaptive capacity as components of vulnerability.

Access to information, services and resources; access to and control over natural resources such as land and water; as well as affordability of basic services such as water, health and credit remained major determining factors causing differential vulnerability. The findings are consistent with and provide further evidences and ground realities to previous research (Adger et al. 2003; IISD 2003; Paavola and Adger 2002; Smith et al. 2000) which indicate that the poor within the communities are differentially affected by the 
impacts of climate change. The finding has an implication for the recently developed climate change policies and frameworks in Nepal (viz., climate change policy 2011; NAPA 2010 and LAPA framework 2011) which effectively ignore the notion of differential vulnerability in terms of analysis and adaptation planning.

The research revealed that climate change vulnerability in the research area is governed by both climatic and non-climatic factors. Many underlying and structural causes were found responsible to make certain groups of people more vulnerable than others. As discussed in the previous section, the marginalization process prevailing in the society was pushing certain families in the communities to live in insecure and marginal lands. Similarly, historically, landless and land poor families are those cultivating in rain-fed marginal uplands and depending upon natural sources of drinking water were found more vulnerable. The impacts of climate change are not the only causes of vulnerability in Nepali society. The very poor and Dalit population in Nepal are historically marginalized and vulnerable based on class, caste, gender and ethnic differences. The analysis of poverty trend in Nepal shows that poverty in Nepal is unevenly distributed and Dalits and marginalized Janajaties living in the rural mountains and hills of Nepal are continuously facing higher incidences of poverty in comparison with the other population (Bennett et al. 2006). The research findings confirm that the impacts of climate change is making a group of people further vulnerable and at risk who are already vulnerable as a result of ongoing poverty, inequality and marginalization. The findings also support the view that addressing climate change vulnerability of the most vulnerable may not be possible without addressing issues related to social exclusion and marginalization as these issues remain a major obstacle for the empowerment of marginalized and socially excluded people in Nepal (Bennett et al. 2006; Murshed and Gates 2005). The findings show similarity with the pressure and release model of vulnerability (Blaikie et al. 1994; Pelling 2003) which links risks and hazards with underlying causes of vulnerability from the political economy framework.

The research found that household vulnerability is more strongly determined by wellbeing status than by geographical location. The findings suggest and justify that the local communities as unit of vulnerability analysis and most vulnerable communities as prioritized groups for adaptation planning. The finding has practical implications to an approach of vulnerability analysis and adaptation planning considering geographical area as a unit. Both NAPA and LAPA frameworks in Nepal are oriented towards addressing climate hazards, ignoring socio-political and underlying causes of vulnerability and lacking a process to identify and target the most vulnerable population. This process may result in an inaccurate vulnerability analysis and further paralyse the adaptation needs of the most vulnerable communities. This research suggests that climate change vulnerability is a complex process which requires analysis of vulnerability at multiple scales (location, timeframe and population units), multiple disciplines (actors, institutions and roles) and multiple causes (underlying causes related to structure, policy and systems) as indicated in some previous literature (Adger 2006; Oreskes 2004; Ribot 2010). A micro-level analysis of vulnerability may help in understanding the complexities and in designing adaptation at the local level. However, the accuracy is based on relevancy of indicators, and reliability of local responses including well-being ranking and stratification of households.

Acknowledgments We honour the contribution of people in the research site for their responses, opinions and support during the field visit. We would like to thank Charles Sturt University and Institute for Land, Water and Society (ILWS) for hosting this research. 


\section{References}

Adams AM, Evans TG, Mohammed R, Farnsworth J (1997) Socioeconomic stratification by wealth rankingis it valid? World Dev 25(7):1165-1172

Adger WN (1999) Social vulnerability to climate change and extremes in coastal Vietnam. World Dev 27(2):249-269

Adger WN (2006) Vulnerability. Glob Environ Change 16(3):268-281

Adger WN, Huq S, Brown K, Conway D, Hulme M (2003) Adaptation to climate change in the developing world. Prog Dev Stud 3(3):179-195

Adger WN, Brooks N, Bentham G, Agnew M, Ereksen S (2004) New indicators of vulnerability and adaptive capacity. Tyndall Centre for Climate Change Research, Norwich

Agrawal A, Perrin N (2008) Climate adaptation, local institutions and rural livelihoods. IFRI Working Paper \# W081-6 (pp. 350-367), University of Michigan, Michigan

Agrawala S, Raksakulthai V, van Aalst M, Larsen P, Smith J, Reynolds J (2003) Development and climate change in Nepal: focus on water resources and hydropower. Organisation for Economic Cooperation and Development (OECD), Paris

Ayers JM, Huq S (2009) The value of linking mitigation and adaptation: a case study of Bangladesh. Environ Manag 43(5):753-764

Bates B, Kundzewicz ZW, Wu S, Palutikof J (2008) Clim change and water. Intergovernmental Panel on Climate Change (IPCC)

Bennett L, Tamang S, Onta P, Thapa M (2006) Unequal citizens- gender, caste and ethnic exclusion in Nepal. Department for International Development and The World Bank, Kathmandu

Blaikie P, Cannon T, Davis I, Wisner B (1994) At risk: natural hazards, people's vulnerability, and disasters. Routledge, London

Brown K (2011) Sustainable adaptation: an oxymoron? Clim Dev 3(1):21-31

Burton I (1997) Vulnerability and adaptive response in the context of climate and climate change. Clim Change 36(1):185-196

Burton I, Kates RW, White GF (1993) The environment as hazard. Guilford, New York

Chambers R (1983) Rural development: putting the last first. Longman, United Kingdom

Chambers R (1994) Participatory rural appraisal (PRA): analysis of experience. World Dev 22(9):1253-1268

Chambers R, Conway GR (1992) Sustainable rural livelihoods-practical concepts for the 21st century. Institute of Development Studies, University of Sussex

Conway D, Schipper ELF (2011) Adaptation to climate change in Africa: challenges and opportunities identified from Ethiopia. Glob Environ Change 21(1):227-237

Daze A, Ambrose K, Ehrhart C (2009) Climate vulnerability and capacity analysis-handbook. CARE International de Dios HB (2002) Participatory capacities and vulnerabilities assessment: finding the link between disasters and development. Oxfam, UK

Dilley M, Boudreau TE (2001) Coming to terms with vulnerability: a critique of the food security definition. Food Policy 26(3):229-247

DoF (2011) CFUG Database, 2011. Department of Forests. Government of Nepal, Kathmandu

Duncan JMA, Biggs EM, Dash J, Atkinson PM (2013) Spatio-temporal trends in precipitation and their implications for water resources management in climate-sensitive Nepal. Appl Geogr 43:138-146

Ebi KL, Kovats RS, Menne B (2006) An approach for assessing human health vulnerability and public health interventions to adapt to climate change. Environ Health Perspect 114:1930-1934

Ebi KL, Woodruff R, von Hildebrand A, Corvalan C (2007) Climate change-related health impacts in the Hindu Kush-Himalayas. EcoHealth 4(3):264-270

Eriksson M, Jianchu X, Shrestha AB, Vaidya R, Sandstrom K (2009) The changing Himalayas: impact of climate change on water resources and livelihoods in the Greater Himalayas. ICIMOD, Kathmandu

Fussel HM (2007) Vulnerability: a generally applicable conceptual framework for climate change research. Glob Environ Change 17(2):155-167

Gaillard JC, Monteil C, Perrillat-Collomb A, Chaudhary S, Chaudhary M, Chaudhary O et al (2013) Participatory 3-dimension mapping: a tool for encouraging multi-caste collaboration to climate change adaptation and disaster risk reduction. Appl Geogr 45:158-166

Gentle P, Maraseni TN (2012) Climate change, poverty and livelihoods: adaptation practices by rural mountain communities in Nepal. Environ Sci Policy 21:24-34

Gippner O, Dhakal S, Sovacool BK (2012) Microhydro electrification and climate change adaptation in Nepal-socioeconomic lessons from the Rural Energy Development Program (REDP). Mitig and Adapt Strategies for Glob Change 1-21 
GoN (2010) National Adaptation Programme of Action (NAPA). Ministry of Environment, Government of Nepal, Kathmandu

GoN (2011a) Climate Change Policy, 2011. Ministry of Environment, Government of Nepal, Kathmandu

GoN (2011b) National framework on local adaptation plans for action. Government of Nepal, Kathmandu

GoN (2012a) Economic survey, fiscal year 2011/2012. Government of Nepal, Kathmandu

GoN (2012b) National population and housing census 2011 (National Report) (Vol. 01, NPHC 2011). Central Bureau of Statistics, Government of Nepal, Kathmandu

Hahn MB, Riederer AM, Foster SO (2009) The livelihood vulnerability index: a pragmatic approach to assessing risks from climate variability and change-a case study in Mozambique. Glob Environ Change 19(1):74-88

Hedger M, Greeley M, Leavy J (2008) Evaluating climate change: pro-poor perspectives. IDS Bull 39(4):75-80

IFRC (2004) World disasters report 2004. International Federation of the Red Cross and Red Crescent Societies, Geneva

IISD (2003) Livelihoods and climate change-combining disaster risk reduction, natural resources management and climate change adaptation to reduce vulnerability and poverty. Information Paper 2, International Institute for Sustainable Development

IPCC (2001) Climate change 2001: impacts, adaptation and vulnerability. Cambridge University Press, Cambridge

IPCC (2007) Assessment of adaptation practices, options, constraints and capacity. Climate Change 2007impacts, adaptation and vulnerability. Contribution of working group II to the fourth assessment report. Cambridge University Press, Cambridge

Johnson RB, Onwuegbuzie AJ, Turner LA (2007) Toward a definition of mixed methods research. J Mix Methods Res 1(2):112-133

King N, Horrocks C (2010) Interviews in qualitative research. Sage Publications, London

Kohler T, Giger M, Hurni H, Ott C, Wiesmann U, Wymann von Dach S et al (2010) Mountains and climate change: a global concern. Mt Res Dev 30(1):53-55

Macchi M (2011) Framework for climate-based climate vulnerability and capacity assessment in mountain areas. International Centre for Integrated Mountain Development (ICIMOD), Kathmandu

Maple Croft (2010) Climate change risk report 2009/10. http://maplecroft.com/about/news/ccvi.html Retrieved 03 April 2013

Mertz O, Halsnæs K, Olesen JE, Rasmussen K (2009) Adaptation to climate change in developing countries. Environ Manag 43(5):743-752

Mirza MMQ (2010) Climate change, flooding in South Asia and implications. Reg Environ Change 1-13

Mosse D (1994) Authority, gender and knowledge: theoretical reflections on the practice of participatory rural appraisal. Dev Change 25(3):497-526

Murshed SM, Gates S (2005) Spatial-horizontal inequality and the Maoist insurgency in Nepal. Rev Dev Econ 9(1):121-134

NCVST (2009) Vulnerability through the eyes of vulnerable-climate change induced uncertainties and Nepal's development predicaments. Climate Vulnerability Study Team (NCVST), Kathmandu

O’Brien K, Leichenko R, Kelkar U, Venema H, Aandahl G, Tompkins H et al (2004) Mapping vulnerability to multiple stressors: climate change and globalization in India. Glob Environ Change 14:303-313

O'Brien K, Eriksen S, Nygaard LP, Schjolden A (2007) Why different interpretations of vulnerability matter in climate change discourses. Clim Policy 7(1):73-88

Oreskes N (2004) The scientific consensus on climate change. Science 306 (1686)

Paavola J, Adger WN (2002) Justice and adaptation to climate change. Tyndall Centre Working Paper, 23

Paavola J, Adger WN (2005) Institutional ecological economics. Eco Econ 53(3):353-368

Pasteur K (2010) From vulnerability to resilience: a framework for analysis and action to build community resilience. Practical Action, UK

Pelling M (Ed.) (2003) Natural disasters and development in a globalizing world. Psychology Press, New York

Picketts IM, Déry SJ, Curry JA (2013) Incorporating climate change adaptation into local plans. J Environ Plan Manag 2013:1-19

Polsky C, Neff R, Yarnal B (2007) Building comparable global change vulnerability assessments: the vulnerability scoping diagram. Glob Environ Change 17:472-485

Ribot J (2010) Vulnerability does not fall from the sky: toward multiscale, pro-poor climate policy. In: Means R, Norton A (eds) Social dimensions of climate change: equity and vulnerability in a warming world. The World Bank, Washington, DC, pp 47-74

Richards M, Maharjan M, Kanel K (2003) Economics, poverty and transparency: measuring equity in forest user groups. J For Live 3(1):91-104 
Saito N (2012) Mainstreaming climate change adaptation in least developed countries in South and Southeast Asia. Mitig Adapt Strateg Glob Change 18:825-849

Scoones I (1995) Investigating difference: applications of wealth ranking and household survey approaches among farming households in Southern Zimbabwe. Dev Change 26(1):67-88

Sen A (1999) Development as freedom. Oxford University Press, Oxford

Sharma AR (2010) Impact of community forestry on income distribution: with case studies from Nepal. Lambert Academic Publishing, Sarbrucken

Shrestha AB, Wake CP, Mayewski PA, Dibb JE (1999) Maximum temperature trends in the Himalaya and its vicinity: an analysis based on temperature records from Nepal for the period 1971-1994. J Clim 12(9):2775-2786

Shrestha AB, Wake CP, Dibb JE, Mayewski PA (2000) Precipitation fluctuations in the Nepal Himalaya and its vicinity and relationship with some large scale climatological parameters. Int J Clim 20(3):317-327

Smith B, Burton I, Klein RJT, Wandel J (2000) An anatomy of adaptation to climate change and variability. Clim Change 45(1):223-251

Springate-Baginski O, Blaikie PM (2007) Forests, people and power: the political ecology of reform in South Asia. Earthscan/James \& James, London

Tanner T, Mitchell T (2008) Entrenchment or enhancement: could climate change adaptation help to reduce chronic poverty? IDS Bull 39(4):6-15

Tashakkori A, Teddlie C (2003) Handbook of mixed methods in social \& behavioral research. Sage Publications, Thousand Oaks

Terry G (2009) No climate justice without gender justice: an overview of the issues. Gend Dev 17(1):5-18

Tubiello FN, Fischer G (2007) Reducing climate change impacts on agriculture: global and regional effects of mitigation, 2000-2080. Technol Forecast Soc Chang 74(7):1030-1056

Urothody A, Larsen H (2010) Measuring climate change vulnerability: a comparison of two indexes. Banko Janakari 20(1):9-11

Vincent K, Cull T (2010) A household social vulnerability index (HSVI) for evaluating adaptation projects in developing countries. PEGNet conference 2010- policies to foster and sustain equitable development in times of crises, Midrand

World Bank (2009) South Asia-shared views on development and climate change. The World Bank, Washington DC

Xu J, Shrestha A, Vaidya R, Eriksson M, Hewitt K (2007) The melting Himalays-regional challenges and local impacts of climate change on mountain ecosystems and livelihoods. ICIMOD, Kathmandu 